\title{
A POSSIBILIDAde JURídica de UNião ESTÁVEL OU CASAMENTO ENTRE MAIS DE DUAS PESSOAS: INTERPRETAÇÃO CONFORME A CONSTITUIÇÃO
}

\author{
Vladimir Polízio \\ Júnior ${ }^{1}$
}

\section{Resumo}

A união estável ou o casamento não monogâmico tem amparo constitucional nos mesmos princípios adotados pelo STF no reconhecimento das uniões homossexuais. $\mathrm{O}$ Estado, que é laico, não pode se omitir diante de um fato social e tratar de modo diferenciado quem busca sua felicidade de forma não convencional; pelo contrário, deve interferir para proteger e resguardar as pessoas que se unem sob um conceito cada vez mais amplo de família, cujo liame subjetivo deve se pautar no amor familiar, na comunhão e na identidade dos seus membros. A família, monogâmica ou não, é a base da sociedade; da mesma forma que não pode ser limitada pela identidade do sexo dos que, unidos pelo amor, reciprocamente se nutrem de afeto, de respeito, de carinho, de compreensão, de apoio, também não pode deixar de ser reconhecida quando for plúrima, sob pena de se violar direito individual daqueles que optam assim viver. Discriminação e preconceito não se coadunam aos princípios republicanos da Constituição Federal, da qual emana supremo o princípio da dignidade da pessoa humana, com suas diversas particularidades.

Palavras-chave: União Plúrima, União Múltipla, Poligamia, União Poliafetiva, Direitos Fundamentais.

\section{INTRODUÇÃO}

Não é apenas a garantia constitucional de liberdade religiosa que ampara a possibilidade jurídica de se regularizar um relacionamento plúrimo, porque o direito de ter reconhecida a união estável ou de casamento entre mais de duas pessoas advém,

\footnotetext{
${ }^{1}$ Vladimir Polízio Júnior é Defensor Público Estadual no Espírito Santo, professor universitário, Mestre em Direito Processual Constitucional e Doutorando em Direito Constitucional na Universidad Nacional de Lomas de Zamora, Argentina. E-mail: vladimirpolizio@gmail.com vol.08, $n^{\circ}$. 01, Rio de Janeiro, 2015. pp. 51-80 51
} 
antes, do direito humano fundamental de primazia da dignidade da pessoa humana. Dignidade pressupõe, pois, não ser recriminado nem discriminado por escolhas pessoais, que dizem respeito apenas e tão somente à vida íntima e privada, que não podem ser tolhidas ou reprimidas por preconceito moral.

O Estado não pode tutelar o indivíduo sobre aspectos relacionados à sua intimidade, sobre quem e como deve amar. Nesse ponto, o julgamento pelo STF da ADI no 4.277/DF (2011), que reconheceu aos casais homoafetivos idênticos direitos daqueles conferidos aos casais heteroafetivos, representou o amadurecimento do constitucionalismo brasileiro, pois confirmou o princípio da dignidade da pessoa humana como vetor para os demais princípios constitucionais, com repercussões em todo o ordenamento.

A busca da felicidade, pois, não pode ser embargada por preconceitos morais que repudiam a diversidade; a base para a construção de um Estado Democrático de Direito está justamente na pluralidade, na convivência pacífica e harmoniosa com o diferente. A família formada por um homem e uma mulher não é diferente daquela formada por duas mulheres ou por dois homens, porque o sentimento que os une e os tornam partícipes dessa sociedade invisível denominada família é o amor, não somente o amor sexual, mas também, e sobretudo, aquele oriundo do companheirismo, do carinho, do afeto, do respeito, da cumplicidade dos seus membros. Da mesma forma, se mais de duas pessoas se unem com os mesmos sentimentos dos casais monogâmicos, não há lastro jurídico constitucional possível para impedir igual tratamento: essa nova espécie de família pode viver em união estável ou regularizar a relação por casamento civil.

\section{DOS FUNDAMENTOS CONSTITUCIONAIS}

Dentre os fundamentos republicanos estabelecidos pelo constituinte de 1988 está "a dignidade da pessoa humana” (art. 1, III). Esse princípio, como explica Moraes (2011, p. 24), "concede unidade aos direitos e garantias fundamentais, sendo inerente às personalidades humanas", e afasta a noção "de predomínio das concepções transpessoalistas de Estado e Nação, em detrimento da liberdade individual". Ferraz 
Filho (2013, p. 5) o define como "valor- fonte de todos os direitos fundamentais", e completa:

Esse valor, que se apresenta como fundamento e fim último de toda a ordem política, busca reconhecer não apenas que a pessoa é sujeito de direitos e créditos diante dessa ordem, mas que é um ser individual e social ao mesmo tempo. [...] Sucede que o ser humano se completa e se plenifica com a presença de todas as dimensões em um contexto harmônico, interdisciplinar e interativo. Isso é que vai, em última análise, permitir a democracia e a atualidade dos direitos fundamentais, a dignidade da pessoa humana constitui, por assim dizer, um valor único e individual, que não pode, seja qual for o pretexto, ser sacrificado por interesses coletivos.

No STF, o ministro Ayres Britto, ao discorrer sobre a dignidade da pessoa

humana no julgamento da ADI no 4.277/DF (2011, p. 14), assim entendeu o alcance da expressão:

34. Óbvio que, nessa altaneira posição de direito fundamental e bem de personalidade, a preferência sexual se põe como direta emanação do princípio da "dignidade da pessoa humana" (inciso III do art. $1^{-}$da CF), e, assim, poderoso fator de afirmação e elevação pessoal. De autoestima no mais elevado ponto da consciência. Autoestima, de sua parte, a aplainar o mais abrangente caminho da felicidade, tal como positivamente normada desde a primeira declaração norte-americana de direitos humanos (Declaração de Direitos do Estado da Virgínia, de 16 de junho de 1776) e até hoje perpassante das declarações constitucionais do gênero. Afinal, se as pessoas de preferência heterossexual só podem se realizar ou ser felizes heterossexualmente, as de preferência homossexual seguem na mesma toada: só podem se realizar ou ser felizes homossexualmente. Ou "homoafetivamente", como hoje em dia mais e mais se fala, talvez para retratar o relevante fato de que o século XXI já se marca pela preponderância da afetividade sobre a biologicidade. Do afeto sobre o biológico, este último como realidade tãosomente mecânica ou automática, porque independente da vontade daquele que é posto no mundo como consequência da fecundação de um individualizado óvulo por um também individualizado espermatozoide.

A dignidade da pessoa humana, pois, contém um princípio implícito, que dele decorre naturalmente, que assegura a todos o direito de perseguir a felicidade. Nesse sentido ementa de lavra do Min. Celso de Mello, do STF, relator do RE no 477.554 (2011):

DIGNIDADE DA PESSOA HUMANA E BUSCA DA FELICIDADE. - O postulado da dignidade da pessoa humana, que representa vol.08, $\mathrm{n}^{\circ}$. 01, Rio de Janeiro, 2015. pp. 51-80 53 
considerada a centralidade desse princípio essencial (CF, art. $1^{\underline{o}}$, III) significativo vetor interpretativo, verdadeiro valor-fonte que conforma e inspira todo o ordenamento constitucional vigente em nosso País, traduz, de modo expressivo, um dos fundamentos em que se assenta, entre nós, a ordem republicana e democrática consagrada pelo sistema de direito constitucional positivo. Doutrina. - O princípio constitucional da busca da felicidade, que decorre, por implicitude, do núcleo de que se irradia o postulado da dignidade da pessoa humana, assume papel de extremo relevo no processo de afirmação, gozo e expansão dos direitos fundamentais, qualificando-se, em função de sua própria teleologia, como fator de neutralização de práticas ou de omissões lesivas cuja ocorrência possa comprometer, afetar ou, até mesmo, esterilizar direitos e franquias individuais. - Assiste, por isso mesmo, a todos, sem qualquer exclusão, o direito à busca da felicidade, verdadeiro postulado constitucional implícito, que se qualifica como expressão de uma ideia-força que deriva do princípio da essencial dignidade da pessoa humana. Precedentes do Supremo Tribunal Federal e da Suprema Corte americana. Positivação desse princípio no plano do direito comparado.

Dessarte, o princípio constitucional da dignidade da pessoa humana constitui a garantia reconhecida pelo constituinte de 1988 de que o ser humano deve ser tratado com dignidade, a qual pressupõe respeito às suas convicções pessoais, porque ele possui o direito de ser feliz. No aspecto individual, essa dignidade se revela na não submissão ao interesse coletivo, de modo que a busca da felicidade não pode ser obstada pela eventual norma restritiva. Essa garantia, como salientou em seu voto o Ministro Ayres Britto, já estava consignada na Declaração de Direitos do Estado da Virgínia, de 1776, que no seu item 1 estabelecia:

Que todos os homens são, por natureza, igualmente livres e independentes, e possuem certos direitos inatos, dos quais, quando entram em estado de sociedade, não podem, por qualquer contrato, privar ou despojar sua posteridade; ou seja, o gozo da vida e da liberdade com os meios de adquirir e possuir propriedades, e de buscar e obter felicidade e segurança ${ }^{2}$.

A Constituição Federal também dispõe, ao elencar os objetivos fundamentais republicanos, a obrigação de "promover o bem de todos, sem preconceitos de origem, raça, sexo, cor, idade e quaisquer outras formas de discriminação" (art. $3^{\text {on }}$ IV). Disso deflui que a promoção do bem comum, que é o bem estar coletivo, sem diferenças entre uns e outros, é o escopo do Estado Nacional. Sobre o tema, oportuna advertência de Agra (2012, p. 181):

\footnotetext{
${ }^{2}$ Tradução livre.
} 
Quando a Constituição fala que não pode haver preconceito em relação a raça, sexo, cor, idade, origem etc., não está falando, de forma absoluta, que é impossível qualquer tipo de discriminação com base nestes elementos. Por exemplo, pode haver diferenciação de sexo, possibilitando a inscrição de apenas mulheres, em um concurso para trabalhar como carcereira em um presídio feminino. Portanto, o que a Constituição veda são diferenciações com base nos elementos mencionados que não tenham um amparo lógico plausível que os justifique, que eles sejam alçados a critérios diferenciadores sem uma forte motivação que os ampare.

Lembra Ferraz Filho (2013, p. 8) que o bem comum, inerente a "todos os seres humanos", constitui o "fim último da democracia constitucional brasileira", advertindo que não se trata de "um ideal irrealizável”. Agra (2012, p. 129) lembra que os objetivos fundamentais constituem princípios de conteúdo polissêmico, "que impedem definições precisas acerca de sua essência", concluindo que "formam as normas do welfare state brasileiro, isto é, são normas programáticas que têm o objetivo de criar um Estado de bem-estar social. Possuem eficácia mediata, no sentido de que o legislador infraconstitucional não pode afrontar o conteúdo de suas disposições”.

O princípio constitucional do bem comum, sem quaisquer formas de preconceito ou discriminação, portanto, reconhece o direito humano inerente a todos individualmente de não serem diferenciados indevidamente. Nesse mesmo sentido também dispõe o caput do art. 5ํㅜㄹ da Carta Política, encartado no Capítulo I, "Dos Direitos e Deveres Individuais e Coletivos", inserido no Título II, denominado "Dos Direitos e Garantias Fundamentais”, de lavra do constituinte de 1988:

Art. $5^{\circ}$ Todos são iguais perante a lei, sem distinção de qualquer natureza, garantindo-se aos brasileiros e aos estrangeiros residentes no País a inviolabilidade do direito à vida, à liberdade, à igualdade, à segurança e à propriedade, nos termos seguintes:

[...]

X - são invioláveis a intimidade, a vida privada, a honra e a imagem das pessoas, assegurado o direito a indenização pelo dano material ou moral decorrente de sua violação;

Aponta Peña de Moraes (2013, p. 321) que "Os direitos fundamentais, especialmente os direitos individuais, procedem à limitação do poder político na medida em que estatuem, relativamente ao Estado e aos particulares, um dever de 
abstenção, isto é, asseguram a existência de uma esfera de ação própria, inibidora de interferências indevidas, de forma que são satisfeitos por um abster-se ou não atuar".

Seriam tais direitos, assim, exemplos do que denominou Georg Jellinek status negativus ou status libertatis, porque consistiriam, os direitos individuais, decorrentes da inação estatal. Alexy (2012, p. 258), ao discorrer sobre essa teoria, aponta que nessa situação estariam apenas as ações consideradas, para o Estado, juridicamente irrelevantes, como "o saborear de um vinho e o passeio em sua própria propriedade". Isso porque ao conceito de status negativo, como aponta Novelino (2013, p. 381), hodiernamente são conferidos dois significados: (i) em sentido stricto, oriundo do pensamento de Jellinek, "diz respeito exclusivamente a liberdades jurídicas não protegidas"; (ii) em sentido lato, acolhido majoritariamente pela doutrina, "se refere aos direitos de defesa, ou seja, direitos a ações negativas do Estado que protegem o status negativo em sentido estrito", ocasionando "uma obrigação negativa endereçada ao Estado para que deixe de fazer algo".

Ciente das inúmeras críticas à teoria dos status de Jellinek, Alexy (2012, p. 270271) lembra que "o legislador está vinculado aos direitos fundamentais", sendo inaplicáveis essas teses "sob a vigência da Constituição alemã". E adverte:

Mas isso não significa que o conceito de status negativo tenha se tornado obsoleto. Quando da discussão acerca do conceito de liberdade jurídica não-protegida foi demonstrado que as normas de direitos fundamentais devem ser concebidas também como normas permissivas. A partir dessa base é possível construir o conceito de status negativo fundamental. $\mathrm{O}$ conceito do status negativo fundamental [...] é constituído pela totalidade daquilo que lhe é facultado em virtude de uma norma constitucional permissiva. O status negativo fundamental pode ser violado também pelo legislador, como, por exemplo, por meio de estabelecimento de normas proibitivas que contradigam uma norma de direito fundamental permissiva. O problema do conteúdo do status negativo é solucionável, portanto, por meio da introdução do conceito de status negativo fundamental ${ }^{3}$.

A doutrina de Alexy, ainda que amparada na realidade alemã, é pertinente de estudo porque também a Constituição brasileira limita a atuação do legislador superveniente, que está adstrita aos direitos fundamentais nela consagrados. Os direitos

\footnotetext{
${ }^{3}$ Grifo nosso.
} 
e garantias individuais assegurados pelo constituinte de 1988, portanto, tutelam o que deve ser resguardado pelo Poder Público em favor dos indivíduos que compõem a sociedade, seja através da ação, normatizando e disciplinando o exercício de alguns direitos e garantias, seja por meio da inação, não diminuindo o campo da legalidade do que se é constitucionalmente assegurado.

A garantia do direito à inviabilidade da intimidade e da vida privada (inc. X, art. $5^{\circ}$, CF), nesse diapasão, nada mais é que a positivação do direito humano de não ser devassado na sua intimidade ou privacidade; a vida em sociedade não obsta do ser humano a garantia do direito ao sigilo de sua vida pessoal e, consequentemente, de liberdade para agir, nessa seara, da forma que bem desejar, desde que não incorra em ilicitude. Para Ferraz Filho (2013, p. 19), "a intimidade está intrinsicamente ligada à própria vida privada", daí ser garantida a "inviolabilidade da esfera privada", porque "o privado é fundamental para o desenvolvimento biológico e para a satisfação das necessidades vitais da pessoa humana", e pode ser desfrutado pela pessoa "individualmente ou em pequenos grupos".

\section{DA UNIÃO HOMOAFETIVA}

A Lex Mater estabelece, na cabeça do art. 226, que "A família, base da sociedade, tem especial proteção do Estado", asseverando que "Para efeito da proteção do Estado, é reconhecida a união estável entre o homem e a mulher como entidade familiar, devendo a lei facilitar sua conversão em casamento" ( $\$ 3^{\circ}$ do art. 226, CF). Na parte em que disciplina a união estável, o Código Civil, no seu art. 1.723, dispõe ser "reconhecida como entidade familiar a união estável entre o homem e a mulher, configurada na convivência pública, contínua e duradoura e estabelecida com o objetivo de constituição de família”.

Com base tão só nos dispositivos mencionados, poucos eram os julgados que buscavam fundamentação em direitos fundamentais para divergir do aparente imperativo da diversidade de sexos. No STJ (2005) já se decidiu:

1. A primeira condição que se impõe à existência da união estável é a dualidade de sexos. A união entre homossexuais 
juridicamente não existe nem pelo casamento, nem pela união estável, mas pode configurar sociedade de fato, cuja dissolução assume contornos econômicos, resultantes da divisão do patrimônio comum, com incidência do Direito das Obrigações.

Não se falava, portanto, em união estável que não fosse entre um homem e uma mulher. Na prática, estavam excluídas da proteção estatal entidades familiares formadas por pessoas do mesmo sexo.

No direito comparado, o tema é controverso. Sabrina Ragone (2013, p. 241), comparando a jurisprudência da Europa sobre o assunto, concluiu que "O reconhecimento de formas de proteção para casais do mesmo sexo é um dos mais atuais desafios dos sistemas jurídicos europeus"4.

Mas o direito não é estanque, e a jurisprudência nacional, acompanhando a melhor doutrina, entende que o alcance dos direitos fundamentais não deve ser menor do que aquele adequado para atender as necessidades da sociedade em um determinado momento. Sem essa interpretação consentânea do Texto constitucional, os conflitos imanentes da própria evolução social não seriam enfrentados com justiça; mais que isso, os fundamentos pretendidos pelo Estado Democrático de Direito brasileiro, como a dignidade da pessoa humana e a promoção do bem comum, seriam lançados meramente à condição de normas programáticas. Daí porque José Afonso da Silva (2013, p. 469), ao dispor sobre a eficácia dos direitos fundamentais, assenta que "a garantia das garantias consiste na eficácia e aplicabilidade imediata das normas constitucionais". O atual ministro do STF, Luís Roberto Barroso (2013, p. 334-335), é preciso em seu escólio:

A nova interpretação constitucional surge para atender às demandas de uma sociedade que se tornou bem mais complexa e plural. Ela não derrota a interpretação tradicional, mas vem para atender às necessidades deficientemente supridas pelas fórmulas clássicas. Tomese como exemplo o conceito constitucional de família. Até a Constituição de 1988, havia uma única forma de se constituir família legítima, que era pelo casamento. A partir da nova Carta, três modalidades de família são expressamente previstas no texto constitucional: a família que resulta do casamento, a que advém das uniões estáveis e as famílias monoparentais. Contudo, por decisão do Supremo Tribunal Federal, passou a existir uma nova espécie de família: a que decorre de uniões homoafetiva. Veja-se, então, que onde havia unidade passou a existir uma pluralidade.

\footnotetext{
${ }^{4}$ Tradução livre.
} 
A nova interpretação incorpora um conjunto de novas categorias, destinadas a lidar com as situações mais complexas e plurais [...]. Dentre elas, a normatividade dos princípios (como dignidade da pessoa humana, solidariedade, segurança jurídica), as colisões de normas constitucionais, a ponderação e a argumentação jurídica. Nesse novo ambiente, mudam o papel da norma, dos fatos e do intérprete. A norma, muitas vezes, traz apenas um início de solução, inscrito em um conceito indeterminado ou em um princípio. Os fatos, por sua vez, passam a fazer parte da normatividade, na medida em que só é possível construir a solução constitucionalmente adequada a partir dos elementos do caso concreto. E o intérprete, que se encontra na contingência de construir adequadamente a solução, torna-se coparticipante do processo de criação do Direito.

De fato, em 2011 o STF, no julgamento da ADI no 4.277/DF, reconheceu a

inexistência de vedação constitucional para que duas pessoas do mesmo sexo constituíssem família. Da ementa, destacamos:

3. TRATAMENTO CONSTITUCIONAL DA INSTITUIÇÃO DA FAMÍLIA. RECONHECIMENTO DE QUE A CONSTITUIÇÃO FEDERAL NÃO EMPRESTA AO SUBSTANTIVO “FAMÍLIA” NENHUM SIGNIFICADO ORTODOXO OU DA PRÓPRIA TÉCNICA JURÍDICA. A FAMÍLIA COMO CATEGORIA SÓCIO-CULTURAL E PRINCÍPIO ESPIRITUAL. DIREITO SUBJETIVO DE CONSTITUIR FAMÍLIA. INTERPRETAÇÃO NÃO-REDUCIONISTA. O caput do art. 226 confere à família, base da sociedade, especial proteção do Estado. Ênfase constitucional à instituição da família. Família em seu coloquial ou proverbial significado de núcleo doméstico, pouco importando se formal ou informalmente constituída, ou se integrada por casais heteroafetivos ou por pares homoafetivos. A Constituição de 1988, ao utilizar-se da expressão "família", não limita sua formação a casais heteroafetivos nem a formalidade cartorária, celebração civil ou liturgia religiosa. Família como instituição privada que, voluntariamente constituída entre pessoas adultas, mantém com o Estado e a sociedade civil uma necessária relação tricotômica. Núcleo familiar que é o principal lócus institucional de concreção dos direitos fundamentais que a própria Constituição designa por "intimidade e vida privada" (inciso X do art. $5^{\circ}$ ). Isonomia entre casais heteroafetivos e pares homoafetivos que somente ganha plenitude de sentido se desembocar no igual direito subjetivo à formação de uma autonomizada família. Família como figura central ou continente, de que tudo o mais é conteúdo. Imperiosidade da interpretação não-reducionista do conceito de família como instituição que também se forma por vias distintas do casamento civil. Avanço da Constituição Federal de 1988 no plano dos costumes. Caminhada na direção do pluralismo como categoria sócio-político-cultural. Competência do Supremo Tribunal Federal para manter, interpretativamente, o Texto Magno na posse do seu fundamental atributo da coerência, o que passa pela eliminação de preconceito quanto à orientação sexual das pessoas.

4. UNIÃO ESTÁVEL. NORMAÇÃO CONSTITUCIONAL REFERIDA A HOMEM E MULHER, MAS APENAS PARA ESPECIAL PROTEÇÃO 
DESTA ÚLTIMA. FOCADO PROPÓSITO CONSTITUCIONAL DE ESTABELECER RELAÇÕES JURIDDICAS HORIZONTAIS OU SEM HIERARQUIA ENTRE AS DUAS TIPOLOGIAS DO GÊNERO HUMANO. IDENTIDADE CONSTITUCIONAL DOS CONCEITOS DE "ENTIDADE FAMILIAR" E "FAMÍLIA". A referência constitucional à dualidade básica homem/mulher, no $\$ 3^{\circ}$ do seu art. 226, deve-se ao centrado intuito de não se perder a menor oportunidade para favorecer relações jurídicas horizontais ou sem hierarquia no âmbito das sociedades domésticas. Reforço normativo a um mais eficiente combate à renitência patriarcal dos costumes brasileiros. Impossibilidade de uso da letra da Constituição para ressuscitar o art. 175 da Carta de 1967/1969. Não há como fazer rolar a cabeça do art. 226 no patíbulo do seu parágrafo terceiro. Dispositivo que, ao utilizar da terminologia "entidade familiar", não pretendeu diferenciá-la da "família". Inexistência de hierarquia ou diferença de qualidade jurídica entre as duas formas de constituição de um novo e autonomizado núcleo doméstico. Emprego do fraseado "entidade familiar" como sinônimo perfeito de família. A Constituição não interdita a formação de família por pessoas do mesmo sexo. Consagração do juízo de que não se proíbe nada a ninguém senão em face de um direito ou de proteção de um legítimo interesse de outrem, ou de toda a sociedade, o que não se dá na hipótese sub judice. Inexistência do direito dos indivíduos heteroafetivos à sua não-equiparação jurídica com os indivíduos homoafetivos.

Dessarte, embora a Constituição e o Código Civil fossem expressos em asseverar que apenas homem e mulher poderiam formar união estável, pela aplicação dos próprios princípios constitucionais concluiu-se que família, ou entidade familiar, poderia também ser formada entre pessoas do mesmo sexo, seja entre homens, seja entre mulheres. O novel conceito de família, ou de entidade familiar, dada a sinonímia entre ambas as expressões, comprova a evolução do direito nacional. No STF está pacificado o entendimento de que pessoas do mesmo sexo podem formar união estável, e consequentemente família5; em 2013, por meio da Resolução no175, o Conselho Nacional de Justiça- CNJ estabeleceu ser vedado "às autoridades competentes a recusa de habilitação, celebração de casamento civil ou de conversão de união estável”, de sorte que não mais há qualquer divergência sobre a possibilidade de pessoas do mesmo sexo constituírem união estável e, querendo, convertê-la em casamento, ou mesmo em casar-se sem a prévia união, tal qual se permite aos casais heterossexuais.

$\mathrm{Na}$ verdade, a família pode advir de um contrato, que é o casamento, mas também da união estável, relacionamento em que, por perdurar no tempo, cria laços

\footnotetext{
${ }^{5}$ Nesse sentido: RE no 687.432; RE no -477.554 .
} 
afetivos muitas vezes mais sólidos que das uniões contratuais; é consequência de uma situação fática, a qual merece proteção estatal.

Um passo imenso na sedimentação dos direitos e das garantias fundamentais significou o reconhecimento de que pessoas do mesmo sexo, da mesma forma como os de sexo opostos, podem constituir família e juntar-se em união estável ou casamento. Como afirmou em voto o ministro Ayres Britto (2011, p. 14), no julgamento da ADI no 4.277/DF, "os únicos fundamentos para a distinção entre as uniões heterossexuais e as uniões homossexuais, para fins de proteção jurídica sob o signo constitucional da família, são o preconceito e a intolerância, enfaticamente rechaçados pela Constituição já em seu preâmbulo", completando que "Não se pode ceder, no caso, a considerações de ordem moral, exceto por uma, que, ao revés, é indispensável: todos os indivíduos devem ser tratados com igual consideração e respeito" ${ }^{6}$

A união homoafetiva concretiza, assim, o respeito à dignidade da pessoa humana, à autonomia da vontade, à igualdade e, sobretudo, ao sagrado direito de buscar a felicidade. O tratamento anteriormente conferido a essas uniões consistia verdadeira violação aos princípios estabelecidos pelo constituinte de 1988.

\section{DA POLIGAMIA}

As premissas desenvolvidas para conferir aos casais homossexuais igualdade de direitos com os casais heterossexuais são lastreadas em princípios constitucionais, na melhor interpretação que permite o moderno constitucionalismo. Afinal, casais do mesmo sexo havia, mas lhes era subtraído o direito de viver em sociedade em igualdade de direitos com casais heteros; não seria a norma, tampouco a interpretação jurisprudencial, que daria azo ao surgimento da homossexualidade, de muito superada a tese de tratar-se de uma patologia. Como assentado na resolução no 1/99, do Conselho Federal de Psicologia- CFP, "a homossexualidade não constitui doença, nem distúrbio e nem perversão", e não era sem tempo.

O que havia era um nítido descompasso entre a norma e a realidade. Após anos de infindáveis discussões legislativas inócuas, pautadas na moralidade religiosa, houve

\footnotetext{
${ }^{6}$ Grifos no original.
} 
por bem a Suprema Corte sedimentar o avanço rumo à consolidação dos princípios basilares da Carta Magna, permitindo a liberdade de opção entre as pessoas na sua vida íntima e privada, até então alijadas de um tratamento equânime. Prevaleceram, destarte, os princípios da igualdade, da liberdade, da dignidade da pessoa humana, da razoabilidade e da proporcionalidade e, até mesmo, o da segurança jurídica, porque as incertezas com relação às consequências jurídicas das relações homoafetiva geravam insegurança não só aos participantes da relação como para a própria sociedade.

Idênticos argumentos, todavia, podem ser utilizados em outras relações que são fáticas, mas que, por existirem em quantidade menor, não atraem o clamor midiático e tampouco aprofundados estudos jurídicos. São aquelas em a família é constituída pela união de mais de duas pessoas, normalmente um homem com mais de uma mulher. Como lembra Azeredo (2009, p. 45),

Ainda que seja difícil encontrar sujeitos que aceitem a exposição de reconhecer que vivam uma relação consentidamente não monogâmica, até por conta da repulsa e reprovação social - o que, na prática, inviabiliza, até mesmo, uma pesquisa de campo mais aprofundada -, certo é que elas existem. Ainda que sem muita ostensividade, elas são de pleno conhecimento do meio em que estão inseridas, mesmo 'à boca pequena', entreouvida entre conhecidos, vizinhos e porteiros.

Entrementes, não se alija de um direito humano fundamental grupos minoritários, os quais, justamente por não comporem a maioria da sociedade, necessitam de maior proteção. Sobre o tema, oportunas as colocações do Min. Gilmar Mendes, ao discorrer sobre o significado "da união homoafetiva como afirmação de direito de minorias" em voto na ADI no 4.277/DF (2011, p. 778):

É evidente também que aqui nós não estamos a falar apenas da falta de uma disciplina legislativa que permita o desenvolvimento de uma dada política pública. Nós estamos a falar, realmente, do reconhecimento do direito de minorias, de direitos fundamentais básicos. E, nesse ponto, não se trata de ativismo judicial, mas de cumprimento da própria essência da jurisdição constitucional ${ }^{7}$.

Da mesma forma, relacionamentos entre mais de duas pessoas existem e necessitam de proteção estatal. Nessa relação poliafetiva, existam ou não filhos, não podem ser privados seus participantes da constituição de união estável ou, querendo,

\footnotetext{
${ }^{7}$ Grifos no original.
} 
contrair casamento. Não se trata de conferir a essa realidade fática somente os efeitos patrimoniais da relação, e sim a totalidade dos direitos que fazem jus os casais heterossexuais e, hodiernamente, os casais homossexuais.

No direito comparado, a justiça estadunidense de Utah, em 2013, no case Brown v. Buhman, reconheceu a inconstitucionalidade da lei estadual proibitiva da poligamia por violação à liberdade de credo assegurada pela Primeira Emenda à Constituição dos Estados Unidos da América, e julgou procedente o pedido de uma família polígama adepta de uma vertente fundamentalista seguidora do pensamento inicial da Igreja Jesus Cristo dos Santos dos Últimos Dias, na qual a união de um homem com várias mulheres é permitido. Na Europa, como aponta Vaquero (2012, p. 552), o tema é controverso:

Frente à boa vontade da maioria dos muçulmanos europeus, persiste a incompreensível disposição no ânimo de uma minoria que quer impor o caráter totalizador de sua religião contra os valores essenciais da sociedade democrática em que vivem, provocando situações inusitadas, sem juízo nem razão, contra as quais se deve atuar de forma contundente, porque merecem uma resposta firme. Os exemplos têm ocorrido em toda Europa $^{8}$.

Com relação à Espanha, lembra Cardo (2011, p. 15) que o conceito de casamento, assentado "em uma série de valores muito ligados à doutrina católica", constitui uma das principais razões para o não reconhecimento de casamento polígamo realizado em país que o admitem, sobretudo por muçulmanos. O professor destaca que a situação atual “é marcada por uma enorme indefinição", que não pode ser solucionada com a anulação dos demais casamentos, pois (i) nem sempre é fácil identificar o primeiro, havendo ainda a possibilidade de que sejam simultâneos; e (ii) consistiria em forma de discriminação contra o cônjuge com menor tempo de matrimônio. Para solucionar o problema, propõe:

No contexto atual, caracterizado pelo notável incremento da imigração, $\mathrm{o}$ respeito às liberdades ideológica e religiosa, por um lado, e o propósito de impulsionar as medidas de conciliação da vida laboral e familiar, por outro, justificam o reconhecimento dos efeitos dos casamentos polígamos validamente celebrados conforme a lei do país dos contraentes; questão distinta é a conveniência de que o legislador

\footnotetext{
${ }^{8}$ Tradução livre.
} 
introduza certas medidas, de ordem a reduzir o custo econômico e organizativo que teriam de suportar as empresas ${ }^{9}$.

No Reino Unido, viviam em 2008 cerca de 1.000 famílias legalmente em poligamia (FOLLETT, 2008), e os principais problemas enfrentados são com relação aos benefícios sociais e pensão (FAIRBAIRN, 2014). Marie-Aude Labbé (2004, p. 79) sustenta que o ideal para a França seria a adoção de medidas legislativas para "defender uma política de integração dos muçulmanos e de erradicação dos efeitos nefastos da poligamia"10.

A poligamia, contudo, já foi regra entre os seres humanos (REVISTA VEJA, 2012):

É a união reprodutiva entre mais de dois indivíduos de uma mesma espécie. Entre os humanos, já foi a regra. O Velho Testamento faz várias referências ao assunto. $\mathrm{O}$ personagem Jacó, por exemplo, teve duas esposas e 12 filhos, que teriam dado origem às doze tribos de Israel. Ainda é praticada no Oriente Médio e em partes da África e da Ásia, além dos Estados Unidos, onde seitas fundamentalistas, não reconhecidas pela organização principal da religião mórmon, a Igreja de Jesus Cristo dos Santos dos Últimos Dias, permitem o casamento poligâmico. Regulamentada pelo Alcorão, é relativamente comum no mundo islâmico, apesar de estar perdendo adesão. O profeta Maomé chegou a ter 16 esposas, mas hoje o permitido são, no máximo, quatro. Foi proibida no Nepal em 1963, na Índia, parcialmente, em 1955, na China em 1953 e, no Japão, em 1880. Nunca foi permitida no Brasil.

O Brasil é um Estado laico. Entretanto, se abordada a questão apenas sob o aspecto da fé professada, seriam incluídos no manto protetivo da norma apenas os teístas e excluídos os que nada professam, daí porque não nos parece razoável a abordagem sob esse prisma. Isso porque a garantia do direito de ter reconhecida a união estável ou o casamento entre mais de duas pessoas decorre, entre nós, antes mesmo da constitucional liberdade de fé, do impedimento à discriminação de qualquer forma e do direito de se buscar a felicidade, instrumentos pelos quais a dignidade da pessoa humana é eficazmente protegida. Ademais, implicaria no exercício de um direito sob uma condicionante, a permissão ou autorização pela religião seguida, criando uma dificuldade irrazoável para o exercício de uma liberdade inerente da condição de ser

\footnotetext{
9 Tradução livre.

${ }^{10}$ Tradução livre.
} 
humano, porque atrelaria o direito à religião quando, na verdade, o direito deve estar atrelado à sociedade.

Não se trata, pois, do acolhimento, pelo direito, de dogma religioso, mas sim no reconhecimento de uma situação fática, na qual é irrelevante qualquer condicionante de cunho religioso. A religião, aqui, tem relação com a moral e, embora também se refira ao exercício das liberdades individuais intrínsecas do ser humano, não prepondera sobre o direito humano fundamental de se buscar a felicidade, assegurado universalmente independente da fé professada.

Dessarte, o aval da religião para a constituição de família possui relevância apenas no âmbito subjetivo do indivíduo, dado seu aspecto moral. O reconhecimento ou o impedimento na formação de um tipo específico de família, diverso da tradicional união entre um homem e uma mulher, não pode transpassar, no campo da liberdade religiosa, a garantia do direito de ser feliz e de não ser discriminado por isso.

Entretanto, o acolhimento da poligamia, que é a união de um homem com mais de uma mulher, ou da poliandria, que a união de uma mulher com mais de um homem, não atenderiam à premissa constitucional de igualdade entre os seres humanos e de respeito pelo diferente. Na verdade, constitui um irrelevante jurídico a sexualidade dos componentes dessa relação, bastando que seja composta por mais de duas pessoas; não cabe ao direito tutelar o instinto sexual, ou desejo, fenótipo ou genótipo dos que, unidos em família, passam a coabitar. A relevância jurídica surge, portanto, quando esses indivíduos se unem e constituem um núcleo familiar, porque é essa instituição que merece proteção, bem como, individualmente, seus componentes, de nada importando a anatomia do sexo que apresentam.

\section{DA POLIGAMIA NO BRASIL}

No município paulista de Tupã, em agosto de 2012, foi lavrada a primeira escritura pública de união poliafetiva, entre duas mulheres e um homem, na qual restou consignado (INSTITUTO BRASILEIRO DE DIREITO DE FAMÍLIA):

Os declarantes, diante da lacuna legal no reconhecimento desse modelo de união afetiva múltipla e simultânea, intentam estabelecer as regras para garantia de seus direitos e deveres, pretendendo vê-las reconhecidas e 
respeitadas social, econômica e juridicamente, em caso de questionamentos ou litígios surgidos entre si ou com terceiros, tendo por base os princípios constitucionais da liberdade, dignidade e igualdade.

Para José Fernando Simão (2013), "O sistema não concebe, com base em um valor secular, a possibilidade de dupla união como forma de constituição de família", lembrando que "Se sempre existiram famílias poligâmicas e isso não se nega, NUNCA o sistema jurídico brasileiro as admitiu. Muito menos sob a forma de união estável, que como forma de constituição de família, conta com a proteção da Constituição" ${ }^{\text {"1 }}$ Ele argumenta que a escritura firmada em Tupã viola "duas regras que aniquilam qualquer possibilidade de se admitir a bigamia no sistema jurídico brasileiro, uma de ordem civil e outra criminal", aduzindo que o casamento bígamo é causa de nulidade absoluta e que bigamia é conduta típica penal. E conclui:

O Código Civil e a Constituição Federal brasileira não exigem dualidade de sexo como elemento de existência do casamento. Se muda a realidade social, mudam também os elementos de existência do casamento.

Assim, o STJ, ao admitir o casamento de pessoas do mesmo sexo, apenas percebeu que o conceito de casamento se alterou com o passar dos séculos. Não se trata mais de união entre o "homem e a mulher", mas sim de união entre "pessoas".

O mesmo não pode se dizer da poligamia escriturada em Tupã. Não se trata de elemento de existência, mas sim de requisito de validade do negócio jurídico. Havendo causa de proibição legal, seja ela culminada de sanção penal ou civil, a afronta à norma cogente acarreta nulidade absoluta da escritura poligâmica tupanense.

A única conclusão que se chega é que e escritura é nula, nos termos do art. 166, por motivo evidentemente ilícito (contra o direito) e por fraudar norma imperativa que proíbe uniões formais ou informais poligâmicas.

Há projeto de lei no Congresso Nacional, denominado "Estatuto da Família”"2, alvo de inúmeras controvérsias. Tecendo críticas sobre vários pontos, Regina B. T. Silva (2014) entende que a proposta "parte de premissas individualistas, aparentemente baseadas no afeto, mas que pretendem impor em nossa legislação, por meio de engodo linguístico, a devassidão", por que:

\footnotetext{
${ }^{11}$ Destaque no original.

${ }^{12}$ Projeto de Lei do Senado no 470 de 2013.
} 
Consta do título das Entidades Familiares, artigo 14, caput, que "as pessoas integrantes da entidade familiar têm o dever recíproco de assistência, amparo material e moral, sendo obrigadas a concorrer, na proporção de suas condições financeiras e econômicas, para a manutenção da família". E no parágrafo único do mesmo artigo, que "a pessoa casada, ou que viva em união estável, e que constitua relacionamento familiar paralelo com outra pessoa, é responsável pelos mesmos deveres referidos neste artigo, e, se for o caso, por danos materiais e morais". Os amantes terão direito a pensão alimentícia e poderão, ainda, requerer reparação dos danos morais e materiais por falta das mesmas atenções e benesses dadas às famílias oriundas de casamento ou união estável. Isso é poligamia.

O Estatuto chega ao cúmulo, nas suas justificativas, de argumentar que "a realidade social subjacente obriga a todos, principalmente a quem se dedica ao seu estudo, a pensar e repensar o ordenamento jurídico para que se aproxime dos anseios mais importantes das pessoas". Desde quando é anseio social no Brasil que as relações conjugais ou de união estável admitam relações paralelas ou mancebia? Vê-se que o projeto distorce o pensamento social e quer institucionalizar a poligamia.

Além da poligamia velada, o projeto pretende institucionalizar a poligamia consentida. Ora, quem recebe um trio formado por duas mulheres e um homem ou por dois homens e uma mulher em sua casa e lhe diz: "Venha, sente-se e coma à minha mesa"? Ditado que bem representa e resume que relações paralelas não são aceitas pela sociedade e devem ser repudiadas pela legislação e por todas as formas de expressão do Direito.

A questão que se põe, ainda que relevantes os argumentos suscitados, pode ser enfrentada por dois enfoques: (i) o direito individual de buscar a felicidade tem lastro na Constituição Federal, no princípio da dignidade da pessoa humana, contra o qual leis infraconstitucionais não podem se opor; (ii) questões morais dizem respeito à individualidade de cada um, sendo necessário, e até mesmo indispensável numa sociedade pluralista e democrática, primar pela convivência harmoniosa com quaisquer minorias, sejam étnicas, religiosas, sexuais, e até mesmo da forma como constituem família; conviver com o diferente não significa necessariamente concordar e defender esse comportamento, mas sim respeitar o direito individual alheio de buscar a felicidade como melhor lhe aprouver. Oportuno o escólio de Andreas Bucher (2000, p. 129), para 
quem "se pode não querer aceitar a poligamia, mas não se pode- deve- ignorá-la nem rechaça-la completamente sem atribuir-lhe o menor efeito jurídico"13.

\section{DO RELACIONAMENTO CONSENTIDO ENTRE MAIS DE DUAS}

\section{PESSOAS}

A família, considerada base da sociedade e detentora de especial proteção pelo Texto constitucional, não se constitui por um conceito unívoco. Como explica o Min. Ayres Britto, em seu voto na ADI no 4.277/DF (2011, p. 645-646):

Deveras, mais que um singelo instituto de Direito em sentido objetivo, a família é uma complexa instituição social em sentido subjetivo. Logo, um aparelho, uma entidade, um organismo, uma estrutura das mais permanentes relações intersubjetivas, um aparato de poder, enfim. Poder doméstico, por evidente, mas no sentido de centro subjetivado da mais próxima, íntima, natural, imediata, carinhosa, confiável e prolongada forma de agregação humana. Tão insimilar a qualquer outra forma de agrupamento humano quanto a pessoa natural perante outra, na sua elementar função de primeiro e insubstituível elo entre o indivíduo e a sociedade. Ambiente primaz, acresça-se, de uma convivência empiricamente instaurada por iniciativa de pessoas que se vêem tomadas da mais qualificada das empatias, porque envolta numa atmosfera de afetividade, aconchego habitacional, concreta admiração ético-espiritual e propósito de felicidade tão emparceiradamente experimentada quanto distendida no tempo e à vista de todos. Tudo isso permeado da franca possibilidade de extensão desse estado personalizado de coisas a outros membros desse mesmo núcleo doméstico, de que servem de amostra os filhos (consangüíneos ou não), avós, netos, sobrinhos e irmãos. Até porque esse núcleo familiar é o principal lócus de concreção dos direitos fundamentais que a própria Constituição designa por "intimidade e vida privada" (inciso X do art. $5^{\circ}$ ), além de, já numa dimensão de moradia, se constituir no asilo "inviolável do indivíduo", consoante dicção do inciso XI desse mesmo artigo constitucional. $\mathrm{O}$ que responde pela transformação de anônimas casas em personalizados lares, sem o que não se tem um igualmente personalizado pedaço de chão no mundo. E sendo assim a mais natural das coletividades humanas ou o apogeu da integração comunitária, a família

\footnotetext{
${ }^{13}$ Tradução livre.
} 
teria mesmo que receber a mais dilatada conceituação jurídica e a mais extensa rede de proteção constitucional. Em rigor, uma palavra-gênero, insuscetível de antecipado fechamento conceitual das espécies em que pode culturalmente se desdobrar ${ }^{14}$.

Hodiernamente, portanto, o conceito do professor Silvio Rodrigues (1997, p. 5), de que na família "se assentam não só as colunas econômicas, como se esteiam as raízes morais da organização social", daí porque o Estado, "na preservação de sua própria sobrevivência", teria "interesse primário em proteger a família, por meio de leis que lhe assegurem o desenvolvimento estável e a intangibilidade de seus elementos essenciais”, exige a adequação do intérprete para não tolher, do indivíduo, sua dignidade constitucionalmente assegurada. Há várias possibilidades de família, que não pode, nem deve, sujeitar-se à submissão estatal para que receba a proteção estatal. E se existem de fato outras formas de família, cabe ao direito evoluir conforme a evolução da própria sociedade. Neste ponto, oportuno escólio do Min. Luiz Fux, ao proferir seu voto julgamento da ADI no 4.277/DF (2011, p. 667-668):

Poderia dizer-se, com algum cinismo, que se trata de "ato jurídico inexistente", vetusta e míope categorização, felizmente há muito abandonada. (É curioso recordar, aliás, que as clássicas lições do Direito Civil não raro mencionavam, como exemplo de "ato jurídico inexistente", o casamento entre pessoas do mesmo sexo...) Como já se sabia em Roma, ubi societas, ibi jus (onde está a sociedade, está o direito) - o direito segue a evolução social, estabelecendo normas para a disciplina dos fenômenos já postos. Não é diferente neste caso: o ato de constituição da união homoafetiva existe, ocorre e gera efeitos juridicamente relevantes, que, portanto, merecem tratamento pelo direito.

O liame subjetivo que mantem a união familiar é o afeto. Para Louzada (2011, p. 21), "o amor e o afeto independem de sexo, cor ou raça", lembrando ser necessário "que se enfrente o problema, deixando de fazer vistas grossas a uma realidade que bate à porta da hodiernidade, e mesmo que a situação não se enquadre nos moldes da relação estável padronizada"; ainda que o pensamento seja relacionado à união homoafetiva, tem cabimento para qualquer união de pessoas que voluntariamente desejem constituir família. Como apontado pelo Min. Ayres Britto (2011, p. 646), em seu voto na ADI no 4.277/DF,

\footnotetext{
${ }^{14}$ Grifos no original.
} 
Família é, por natureza ou no plano dos fatos, vocacionalmente amorosa, parental e protetora dos respectivos membros, constituindo-se, no espaço ideal das mais duradouras, afetivas, solidárias ou espiritualizadas relações humanas de índole privada. O que a credencia como base da sociedade, pois também a sociedade se deseja assim estável, afetiva, solidária e espiritualmente estruturada (não sendo por outra razão que Rui Barbosa definia a família como 'a Pátria amplificada') ${ }^{15}$.

O afeto, como elemento moderna família, foi identificado na ementa do RE no 477.554 AgR/MG, pelo STF (2011):

A DIMENSÃO CONSTITUCIONAL DO AFETO COMO UM DOS FUNDAMENTOS DA FAMÍLIA MODERNA. - O reconhecimento do afeto como valor jurídico impregnado de natureza constitucional: um novo paradigma que informa e inspira a formulação do próprio conceito de família.

Nesse prisma, não cabe ao Estado tutelar sobre a vida íntima do indivíduo, que possui a garantia do direito de buscar sua felicidade. E se essa felicidade for facilitada num relacionamento hétero, homo ou múltiplo, diz respeito apenas àqueles que compõem a relação, não a terceiros.

A constituição de família, que pode ser fática, superou o limite da diversidade de sexo não pela alteração normativa, mas sim, e isso deve ser ressaltado, pela evolução

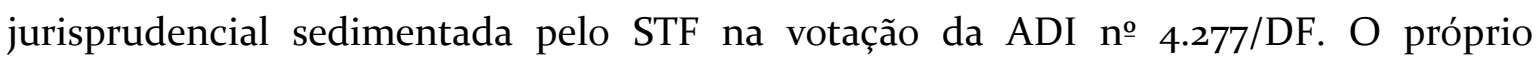
conceito de casal, que para Ferreira (1986, p. 362) exigia diversidade de sexo, hodiernamente também é utilizado para identificar homem e homem ou mulher e mulher.

A multiplicidade de pessoas que, unidas, mantém um relacionamento estável, constitui a nova fronteira a ser enfrentada pelo direito, porque negar-lhes o reconhecimento dessa situação de fato constitui violação a princípios constitucionais sagrados, exatamente àqueles que lastrearam o reconhecimento jurídico da união entre homossexuais. Vejamos:

1. Princípio da Igualdade. A família constituída por mais de duas pessoas não pode ser discriminada porque, como dito na ementa do RE no 477.554 do STF, de lavra do Min. Celso de Mello (2011), "Toda pessoa tem o direito fundamental de constituir família, independente de orientação sexual ou de identidade de

\footnotetext{
${ }^{15}$ Grifo no original.
} 
gênero", resultando que "A família resultante de união homoafetiva não pode sofrer discriminação, cabendo-lhe os mesmos direitos que se mostrem acessíveis a parceiros de sexo distinto que integrem uniões heteroafetivas". Tratar de forma diferenciada família baseada no amor e no afeto porque formada por mais de suas pessoas importa violação ao princípio da igualdade;

2. Princípio da Liberdade. A pessoa que livremente opta por viver num relacionamento múltiplo tem violada a autonomia de sua vontade, impedindo-a de desenvolver sua sexualidade da forma que melhor the aprouver;

3. Princípio da Dignidade da Pessoa Humana. O relacionamento entre mais de duas pessoas merece o reconhecimento, a consideração e o respeito, pois constitui meio de se buscar a felicidade;

4. Princípio da Razoabilidade e da Proporcionalidade. O impedimento para a existência de um relacionamento entre mais de duas pessoas apenas se justificaria se houvesse outro bem jurídico, de igual hierarquia, tutelado; ausente essa condicionante, entretanto, a negativa do reconhecimento do status de família para união entre mais de duas pessoas constitui preconceito moral. No STF, em voto do Min. Celso de Mello (2011, p. 296-297), está dito ser "arbitrário e inaceitável qualquer estatuto que puna, que exclua, que discrimine, que fomente a intolerância, que estimule o desrespeito e que desiguale as pessoas em razão de sua orientação sexual". E completa:

Essa afirmação, mais do que simples proclamação retórica, traduz o reconhecimento, que emerge dos quadros das liberdades públicas, de que o Estado não pode adotar medidas nem formular prescrições normativas que provoquem, por efeito de seu conteúdo discriminatório, a exclusão jurídica de grupos, minoritários ou não, que integram a comunhão nacional.

Esta Suprema Corte, ao proferir referido julgamento, viabilizou a plena realização dos valores da liberdade, da igualdade e da não discriminação, que representam fundamentos essenciais à configuração de uma sociedade verdadeiramente democrática, tornando efetivo, assim, o princípio da igualdade, assegurando respeito à liberdade pessoal e à autonomia individual, conferindo primazia à dignidade da pessoa humana, rompendo paradigmas históricos, culturais e sociais e removendo obstáculos que, até então, inviabilizaram a busca da felicidade por parte de homossexuais vítimas de tratamento discriminatório ${ }^{16}$.

\footnotetext{
${ }^{16}$ Grifos no original.
} 
5. Princípio da Segurança Jurídica. A incerteza sobre as consequências jurídicas do relacionamento entre mais de duas pessoas geram insegurança jurídica para os que dela participam e também para a sociedade. Pilar Juárez Pérez (2012, p. 41) lembra que, na Espanha, a ausência de uma regulamentação sobre a poligamia gera decisões conflitantes, "que vão desde sua tipificação como delito penal até a concessão de importantes efeitos de ordem social”, resultando numa conclusão "tão inevitável quanto lógica: a necessidade de dotar de uma maior segurança e previsibilidade jurídicas as respostas dos nossos tribunais para a instituição da poligamia, que em sua máxima extensão somente pode advir da mão do legislador, que até o momento a tem ignorado quase por completo"17.

\section{DA NECESSIDADE DE INTERPRETAÇÃO CONFORME DO ART. 235 DO CÓDIGO PENAL}

O Código Penal, oriundo do Decreto Lei no 2.848, de 7 de dezembro de 1940, dispõe, no seu artigo 235, que "Contrair alguém, sendo casado, novo casamento", constitui crime de bigamia.

A interpretação conforme a Constituição do mencionado dispositivo, à luz dos direitos humanos fundamentais, encontra tipicidade na conduta daquele que omite do futuro cônjuge sua condição de já casado, desde que não possa ser presumida por todos que participam na relação. Isso porque, se o novo cônjuge passou a coabitar com o casal, não há se falar em fato típico.

O bem juridicamente tutelado, que é o casamento, continua a sê-lo, mas sob esse novo prisma, da boa fé, objetiva e subjetiva, entre os envolvidos na relação.

\section{CONCLUSÃO}

Na vigência do Código Civil de 1916, os filhos havidos fora do casamento eram denominados ilegítimos; com o Código Civil de 2002, todas as diferenças foram abolidas. No Código Civil de 1916 foi introduzido o desquite, que autorizava a separação

\footnotetext{
${ }^{17}$ Tradução nossa.
} 
de corpos mas mantinha o vínculo matrimonial; o divórcio, e o consequente fim do vínculo matrimonial, surgiu em 1977, com a Lei no 6.515 (DIAS, LARRATÉIA). Com a Lei no 11.441, de 2007, casais sem filhos menores ou incapazes podem divorciar-se sem a necessidade de um processo judicial. Ao casamento, que antes se exigia diversidade de sexos, desde 2013 não se faz mais qualquer distinção.

Esses exemplos comprovam o aggiornamento a que se submete o direito para atender a realidade social do seu tempo, pois não é a sociedade que deve adaptar-se ao seu regramento jurídico, e sim este conjunto normativo que deve refletir os instrumentos adequados para atender ao que for necessário na sociedade. Essa evolução, contudo, nem sempre acontece por meio do legislador, porque há situações em que, de uma mesma norma, passa-se a identificar um novo prisma, o qual permite um significado diverso daquele que até então se extraia do texto.

Nesse diapasão, o julgamento da ADI no 4.277/DF, em 2011, pelo STF, representou um divisor de águas, porque interpretou um dispositivo fruto do constituinte de 1988, que previa união estável entre homem e mulher (art. 216, §3ํㅜ $\mathrm{CF}$ ), com princípios fundamentais, também estabelecidos pelo constituinte de 1988; o desfecho foi a prevalência destes sobre aquele. O princípio da dignidade da pessoa humana não pode tolerar discriminações pautadas em um pretenso valor moral divorciado do moderno constitucionalismo, violador do respeito à individualidade, castrador do direito natural e inerente da condição humana de se buscar a felicidade.

De muito há famílias, com e sem filhos, formadas por pessoas do mesmo sexo, mas que eram injustamente alijadas dos iguais direitos concedidos aos casais heterossexuais. O reconhecimento da união homoafetiva, e posteriormente do casamento entre homossexuais, representam um caminho em direção à sedimentação de tão caras garantias.

Entretanto, a evolução do direito é uma constante, porque seu escopo é justamente atender aos anseios da sociedade do seu tempo. O reconhecimento da união homoafetiva, conferindo-lhe iguais direitos aos da heteroafetiva, representa uma conquista de toda a sociedade. Mas não esgota o tema, porque a questão não pode se limitar à identidade do sexo dos que, unidos pelo amor, reciprocamente se nutrem de afeto, de respeito, de carinho, de compreensão, de apoio. A plenitude dos direitos 
fundamentais exige que não haja interferência estatal também sobre a quantidade de pessoas que participam da relação, porque diz respeito apenas àqueles que dela compõem, e que lhes sejam assegurados os mesmos direitos garantidos aos relacionamentos monogâmicos, sejam homo ou heterossexuais.

Como salientou o Min. Luiz Fux, do STF, em seu voto na ADI no 4.277/DF (2011, p. 671),

O que faz uma família é, sobretudo, o amor - não a mera afeição entre os indivíduos, mas o verdadeiro amor familiar, que estabelece relações de afeto, assistência e suporte recíprocos entre os integrantes do grupo. O que faz uma família é a comunhão, a existência de um projeto coletivo, permanente e duradouro de vida em comum. O que faz uma família é a identidade, a certeza de seus integrantes quanto à existência de um vínculo inquebrantável que os une e que os identifica uns perante os outros e cada um deles perante a sociedade. Presentes esses três requisitos, tem-se uma família, incidindo, com isso, a respectiva proteção constitucional $^{18}$.

Dessarte, não é o fato de que um homem se uniu a uma mulher, ou uma mulher se uniu a outra, ou mesmo um homem se uniu a outro, mas sim a presença de um sentimento que ultrapasse os limites do desejo sexual e alcance um patamar superior, ao qual denominou Fux "verdadeiro amor familiar", que nada mais é senão uma afeição singular, personalíssima. Focar no sexo dos indivíduos que compõem a relação é afastar-se do essencial, porque não é a diversidade de sexo que torna um relacionamento feliz e duradouro; o importante é não ceifar as possibilidades inerentes da vida humana que permitam a busca da felicidade. E se essa busca conduz à necessidade de um parceiro do mesmo sexo, ou de múltiplos parceiros, constitui fato irrelevante para o Estado e para o direito, porque relacionado ao exercício da liberdade individual do ser humano.

Compreensão diversa incorreria em discriminação indevida, de verdadeira intromissão em questão afeta à esfera íntima daquele que opta por um relacionamento com mais de duas pessoas, em união poliafetiva, que não pode ser privado de buscar sua felicidade por preconceitos morais. Aliás, o único impedimento seria com base na moral, porquanto nenhuma ilegalidade há na formação fática dessa relação; nem mesmo o crime de bigamia, que pune quem contrai novo casamento sendo casado,

\footnotetext{
${ }^{18}$ Grifos no original.
} 
porque não resiste a uma interpretação consentânea do Texto constitucional pautada na prevalência dos direitos e garantias fundamentais.

De muito a separação entre Igreja e Estado veda que dogmas religiosos tenham amparo jurídico e se tornem impositivos universalmente. O que há, e sempre deve haver, é o respeito entre os semelhantes, sobretudo com quem pensa diferente. $\mathrm{O}$ preconceito e a discriminação, em qualquer sociedade, fomentam o ódio e a discórdia, e não tem lugar em um Estado Democrático e de Direito como o brasileiro.

O reconhecimento da união plúrima, conferindo-lhe as mesmas garantias inerentes à relação estável e do casamento monogâmicos, não constitui um incentivo a essa espécie de composição familiar, mas sim na aplicação da isonomia entre as diversas formas pelas quais essa célula mater da vida social possa se manifestar; não é o Estado quem cria a instituição família, mas sim a sociedade, na medida em que seus indivíduos se unem por laços duradouros. Famílias oriundas de casais homo ou heterossexuais não podem possuir mais direitos que aquelas resultantes da pluralidade de membros.

Destarte, nenhum impedimento existe para que mais de duas pessoas formalizem juridicamente uma situação que de fato já existe. Essa união estável entre as pessoas pode, assim, ser convertida até mesmo para o casamento, desde que presentes os mesmos pressupostos necessários para casais hétero ou homossexuais. No acórdão da ADI no 4.277/DF (2011) ficou assim consignado:

6. INTERPRETAÇÃO DO ART. 1.723 DO CÓDIGO CIVIL EM CONFORMIDADE COM A CONSTITUIÇÃO FEDERAL (TÉCNICA DA "INTERPRETAÇÃO CONFORME”). RECONHECIMENTO DA UNIÃO HOMOAFETIVA COMO FAMÍLIA. PROCEDÊNCIA DAS AÇÕES. Ante a possibilidade de interpretação em sentido preconceituoso ou discriminatório do art. 1.723 do Código Civil, não resolúvel à luz dele próprio, faz-se necessária a utilização da técnica de "interpretação conforme à Constituição". Isso para excluir do dispositivo em causa qualquer significado que impeça o reconhecimento da união contínua, pública e duradoura entre pessoas do mesmo sexo como família. Reconhecimento que é de ser feito segundo as mesmas regras e com as mesmas consequências da união estável heteroafetiva.

Interpretação consentânea do art. 1.723 do Código Civil exige que para união estável haja "união contínua, pública e duradoura entre pessoas como família", excluindo qualquer referência à identidade de sexos ou à quantidade de pessoas, bastando a existência da continuidade do relacionamento entre os parceiros. Sejam 
dois, sejam mais. E reconhecida a possibilidade de união estável, da mesma forma se reconhece a possibilidade de casamento.

O conceito de família, portanto, não pode ser limitado ou reduzido por complexos do legislador; há, como leciona Alexy, um campo de status negativo fundamental, que não pode ser ultrapassado. Uma realidade social não suporta, em um Estado republicano e democrático, ser menoscabada por valores morais segregacionistas. A busca do bem comum, que na sempre atual lição de João XXXII (1963) constitui o "conjunto de todas as condições de vida social que consintam e favoreçam o desenvolvimento integral da personalidade humana”, constitui o fim primeiro e último de qualquer ordenamento, não subsistindo qualquer fundamentação idônea, no campo do moderno constitucionalismo, que impeça isonomia de uniões poliafetivas com o tratamento hodiernamente conferido aos pares homoafetivos na busca de sua felicidade. Todos têm direito de desenvolver integralmente a personalidade e de não ser discriminado por isso.

\title{
THE LEGAL POSSIBILITY OF COMMON-LAW MARRIAGE OR MARRIAGE OVER TWO PEOPLE: INTERPRETATION IN CONFORMITY TO THE CONSTITUTION
}

\begin{abstract}
The non-monogamous common-law marriage or marriage has constitutional protection on the same principles adopted by the Supreme Court in recognition of homosexual unions. The State, which is secular, can not be omissive in the face of a social fact and treat differently those who seek their happiness in an unconventional way; on the contrary, it must interfere to protect and safeguard the people who come together under an increasingly broad concept of Family, whose subjective bond must be based on family love, on communion and on identity of its members. The family, monogamous or not, is the foundation of society; the same way it can not be limited by the sex identity of those who, united by love, reciprocally nourish affection, respect, friendship, understanding, support, it also can not fail to be recognized when multiple, under penalty of violating the individual rights of those who choose living in this manner. Discrimination and prejudice are not consistent with republican principles of the Federal Constitution, from which the supreme principle of human dignity emanates, with its various features.
\end{abstract}


Keywords: MULTIPLE UNION, MULTIPLE MARRIAGE, POLYGAMY, MULTIAFFECTIVE UNION, FUNDAMENTAL RIGHTS.

\section{REFERÊNCIAS}

AGRA, Walber de Moura. Curso de Direito Constitucional. $7^{\underline{a}}$ ed. Rio de Janeiro: Forense, 2012.

ALEXY, Robert. Teoria dos Direitos Fundamentais. Trad. Virgílio Afonso da Silva, $2^{\underline{a}}$ ed. São Paulo: Malheiros, 2012.

AZEREDO, Fabrício Terra de. Relações poligâmicas consentidas: seu reconhecimento como entidade familiar. 2009. Disponível em: < http://www.emerj.tjrj.jus.br/paginas/biblioteca_videoteca/monografia/Monografia_pdf/ 2009/Fabricio\%2oTerra\%2ode\%2oAzeredo\%2oMONOGRAFIA\%2oEM\%2oPDF\%2o(co mpleta).pdf>. Acesso em: 13 ago. 2014.

BARROSO, Luís Roberto. Curso de Direito Constitucional Contemporâneo. $4^{\underline{a}}$ ed. São Paulo: Saraiva, 2013.

BRASIL. CNJ. Resolução no 175, de 14 de maio de 2013. Disponível em < http://www.cnj.jus.br/images/imprensa/resolu\%C3\%A7\%C3\%A30_n_175.pdf>. Acesso em: 14 ago. 2014.

Código Penal. Decreto Lei no $\mathbf{2 . 8 4 8}$, de 7 de dezembro de 1940. Disponível em: $<$ http://www.planalto.gov.br/ccivil_03/decreto-lei/del2848.htm>. Acesso em: 17 ago. 2014.

Lei no 6.515, de 26 de dezembro de 1977. Regula os casos de dissolução da sociedade conjugal e do casamento, seus efeitos e respectivos processos, e dá outras providências. Disponível em: < http://www.planalto.gov.br/ccivil_03/leis/16515.htm >. Acesso em: 18 ago. 2014.

Lei no 10.406, de 10 de janeiro de 2002. Institui o Código Civil. Disponível em: < http://www.planalto.gov.br/ccivil_03/leis/2002/lio406.htm >. Acesso em: 18 ago. 2014.

Lei no 11.441, de 4 de janeiro de 2007. Altera dispositivos da Lei no 5.869, de 11 de janeiro de 1973 - Código de Processo Civil, possibilitando a realização de inventário, partilha, separação consensual e divórcio consensual por via administrativa. Disponível em: < http://www.planalto.gov.br/ccivil_03/_ato2007-2010/2007/lei/l11441.htm >. Acesso em: 19 ago. 2014.

Projeto de Lei do Senado no 470 de 2013. Disponível em < http://www.senado.gov.br/atividade/materia/detalhes.asp?p_cod_mate $=115242>$. Acesso em: 18 ago. 2014.

STF. ADI no 4.277/DF, rel. Min. Ayres Britto, Tribunal Pleno, por unanimidade, j. 05/05/2011, p. DJe 10/10/2011. Disponível em $<$ http://redir.stf.jus.br/paginadorpub/paginador.jsp?docTP=AC\&docID=628635>. Acesso em: 10 ago. 2014. 
.STF. RE no 687.432 AgR/MG, rel. Min. Luiz Fux, Primeira Turma, por unanimidade, j. 18/09/2012, p. DJe 02/10/2012. Disponível em: < http://redir.stf.jus.br/paginadorpub/paginador.jsp?docTP=TP\&docID=2864514>. Acesso em: 12 ago. 2014.

STF. RE no 477.554 AgR/MG, rel. Min. Celso de Mello, Segunda Turma, por unanimidade, j. 16/08/2011, p. DJe o6/o8/2011. Disponível em: < http://redir.stf.jus.br/paginadorpub/paginador.jsp?docTP=AC\&docID=626719> Acesso em: 12 ago. 2014.

STJ. REsp no 502.995/RN, rel. Min. Fernando Gonçalves, Quarta Turma, por unanimidade, j. 26/04/2005, p. DJ 16/05/205. Disponível em: < https://ww2.stj.jus.br/revistaeletronica/Abre_Documento.asp?sLink=ATC\&sSeq=170225 o\&sReg=200201745035\&sData $=20050516 \&$ sTipo $=5 \&$ formato $=$ PDF $>$. Acesso em: 12 ago. 2014 .

BUCHER, Andreas. La famille en droit international privé, v. 283, Recueil des Cours, Collected Courses Series. Leida: Brill Academic Publishers, 2000.

CARDO, Iván Antonio Rodríguez. El derecho del trabajo y las relaciones laborales ante los cambios económicos y sociales. X Congreso Europeo de Derecho del Trabajo y de la Seguridad Social, 21 al 23 de septiembre de 2011, Sevilla. Disponível em: < http://www.tsj.gov.ve/informacion/miscelaneas/congresoeuropeo/o1\%2oPrimera\%2opo nencia/111\%2oRODRIGUEZ\%2oCARDO.pdf >. Acesso em: 21 ago. 2014.

CFP. Resolução no oo1/99, de 22 de março de 1999, que "Estabelece normas de atuação para os psicólogos em relação à questão da Orientação Sexual”. Disponível em: < http://site.cfp.org.br/wp-content/uploads/1999/o3/resoluca01999_1.pdf>. Acesso em: 15 ago. 2014.

DIAS, Maria Berenice. LARRATÉA, Roberta Vieira. Separação de corpos e o desenlace familiar. Disponível em: < http://www.mariaberenice.com.br/uploads/12_-

_separa\%E7\%E30_de_corpos_e_desenlace_familiar.pdf>. Acesso em: 19 ago. 2014.

EUA. The Virginia Declaration of Rights, 1776. Disponível em: < http://www.archives.gov/exhibits/charters/virginia_declaration_of_rights.html >. Acesso em: 10 ago. 2014.

Utah Courts, Case Brown v. Buhman, no 2:11-cv-0652-CW, j. 13/12/2013. Disponível em: <http://lawprofessors.typepad.com/files/brown_utah_bigamy.pdf >. Acesso em: 13 ago. 2014 .

FAIRBAIRN. Catherine. Polygamy- Commons Library Standard Note, o9 may 2014. Disponível em: < http://www.parliament.uk/business/publications/research/briefingpapers/SNo5051/polygamy >. Acesso em: 22 ago. 2014. 
FOLLETT, Barbara. Parliament, 21 jan 20o8: Column 1510W. Disponível em: < http://www.publications.parliament.uk/pa/cm200708/cmhansrd/cmo80121/text/8o121w 0005.htm\#0801219000567>. Acesso em: 22 ago. 2014.

FERRAZ FILHO, José Francisco Cunha. In: Machado, Antônio da Costa (Org.). Constituição Federal Interpretada. $4^{\underline{a}}$ ed. Barueri: Manole, 2013.

FERREIRA, Aurélio Buarque de Holanda. Novo Dicionário Aurélio da Língua Portuguesa. 2ª. Rio de Janeiro: Nova Fronteira, 1986.

Instituto Brasileiro de Direito de Família- IBDFAM. Escritura reconhece união afetiva a três. Disponível em: <http://www.ibdfam.org.br/noticias/4862/novosite>. Acesso em: 19 ago. 2014.

JOÃO XXXIII. Carta Encíclica Pacem in Terris do Sumo Pontífice Papa João XXIII aos veneráveis irmãos patriarcas, primazes, arcebispos, bispos e outros ordinários do lugar em paz e comunhão com a sé apostólica ao clero e fiéis de todo o orbe, bem como a todas as pessoas de boa vontade. 1963. Disponível em: < http://www.vatican.va/holy_father/john_xxiii/encyclicals/documents/hf_jxxiii_enc_11041963_pacem_po.html\#_ftn34>. Acesso em: 15 ago. 2014 .

LABBÉ, Marie-Aude. Droit International Privé et politique d'immigration: L'exemple de la polygamie. Universite Lille 2, Ecole Doctorale des Sciences Juridiques, Politiques et de Gestion. 2004. Disponível em: <http://edoctorale74.univlille2.fr/fileadmin/master_recherche/T_l_chargement/memoires/personnes/labbeao4.p df>. Acesso em: 23 ago. 2014.

LOUZADA, Ana Maria Gonçalves. Evolução do conceito de família. Revista da Escola da Magistratura do Distrito Federal no 13, 2011. Disponível em: <http://www.escoladamagistratura.org.br/site/images/stories/pdf/Revista/revista13.pdf >. Acesso em: 15 ago. 2014.

MORAES, Alexandre de. Curso de Direito Constitucional. 27‥ São Paulo: Atlas, 2011.

MORAES, Peña de. Curso de Direito Constitucional. $5^{\text {a }}$ ed. São Paulo: Atlas, 2013. NOVELINO, Marcelo. Manual de Direito Constitucional. $8^{a}$ ed. São Paulo: Método, 2013.

PÉREZ, Pilar Juárez. Jurisdicción española y poligamia islámica: ¿Un matrimonio forzoso?, Revista Electrónica de Estudios Internacionales- Dialnet, Universidad de la Rioja, 2012. Disponível em: < http://dialnet.unirioja.es/descarga/articulo/4043410.pdf.>. Acesso em: 19 ago. 2014.

RAGONE, Sabrina. El matrimonio homosexual en europa, entre derecho político y derecho jurisprudencial. Reflexiones a raíz de la reciente jurisprudencia comparada. Nueva Época, v. 16, no 1, Madrid, 2013. Disponível em: < 
http://revistas.ucm.es/index.php/FORO/article/download/44472/42003.>. Acesso em: 17 ago. 2014.

Revista Veja. Sociedades poligâmicas são mais violentas, diz pesquisa. São Paulo: Abril, 25/o1/2012. Disponível em < http://veja.abril.com.br/noticia/ciencia/poligamiagera-sociedades-violentas-afirma-pesquisa>. Acesso em: 15 ago. 2014.

RODRIGUES, Silvio. Direito Civil, v. 6, 22⿳ㅗㄹ ed. São Paulo: Saraiva, 1997.

SILVA, Regina Beatriz Tavares da. Destruição da família projetada em lei. ESAEscola Superior de Advocacia da Ordem dos Advogados do Brasil- Seção São Paulo. 2014. Disponível em: <http://www.esaoabsp.edu.br/Artigo.aspx?Art=101>. Acesso em: 19 ago. 2014.

SILVA, José Afonso da. Curso de Direito Constitucional. 24로 ed. São Paulo: Malheiros, 2013.

SIMÃO, José Fernando. Poligamia, casamento homoafetivo, escritura pública e dano social: uma reflexão necessária? Parte 3. São Paulo: Jornal Carta Forense, 01/02/2013. Disponível em < http://www.cartaforense.com.br/conteudo/colunas/poligamia-casamento-homoafetivoescritura-publica-e-dano-social-uma-reflexao-necessaria--parte-3/10376>. Acesso em: 19 ago. 2014 .

VAQUERO, Carlos Pérez. El islam en la sociedad democrática europea: ocho conflictos surgidos en europa, desde una perspectiva jurídica y con especial referencia al caso español- tesis doctoral, Universidad de Villadolid. Disponível em: $<$ https://uvadoc.uva.es/bitstream/10324/2900/1/TESIS323-130530.pdf>. Acesso em: 14 ago. 2014 .

Trabalho enviado em 27 de agosto de 2014.

Aceito em 11 de fevereiro de 2015. 